ii) some discussion of the techniques of advocacy to which the expert witness might expect to be subjected, had been provided. David Cook did just this in his article, 'Being an expert witness', which was published in The Psychologist, in May 1990.

One must look forward to the complete rewriting of this publication which is necessitated by the implementation of the Children Act in October.

See also the excellent, Professionals and the Courts - a Handbook for Export Witnesses by David Carson, published by Venture Press, Leicester with the BASW, 1990.

DR CONSTANCE M DENNEHY Department of Family $\mathcal{G}$ Child Psychiatry

Queen Elizabeth's Hospital for Children Hackney Road London E2 8PS

\section{Teaching Genetics to Medical Students}

Working party of the Committee on Clinical Genetics of the Royal College of Physicians, 32 pages, London, $£ 5.00$, Royal College of Physicians, 1990

The last few years have seen a rapid expansion in knowledge about genetic factors in disease, and also the introduction of many new genetic technologies of actual or potential clinical relevance. The process shows no sign of any slowing down, so this report, produced by a Working Party of the Committee on Clinical Genetics of the Royal Physicians of London, is timely. The report is short and succinct, and its message is clear.

The report reviews current medical undergraduate teaching in genetics at different centres in Britain. Only a small amount of timetabled teaching time is alloted to genetics, the average being a total of around 20 hours during the five-year curriculum. There was wide variation between centres on both the course content and the teaching time, but in almost all medical schools the majority of the genetics teaching formed part of the pre-clinical course.

While recognising that the medical undergraduate curriculum is already overcrowded, the working party concluded that there was an unambiguous and pressing need for the establishment of carefully co-ordinated and clearly delineated genetics teaching in medical schools. They go on to define topics for pre-clinical genetics teaching, and make strong recommendations for strengthening and co-ordinating genetics teaching during the clinical course. A draft syllabus and suggested teaching methods for the clinical course are given in an appendix.

If there is to be more and better teaching, there will need to be an expansion in the numbers of clinical genetics teachers. The report concludes by recommending a task force should be set up to accelerate the pace of change in genetic education.

The introduction of both genetic screening and new technologies has already highlighted many ethical problems. If gene therapy becomes a practical possibility there will be new ethical issues to consider. It was pleasing to see that in a survey of clinicians an appreciation of the major ethical issues in medical genetics and an awareness of the stress caused in families by genetic disease were ranked highly as skills that needed to be taught to clinical students.

Reports are not self-executive. The next steps are awaited with interest.

RICHARD WEST

Consultant and Senior Lecturer Department of Child Health, St George's Hospital, London SW17 ORE

\section{A Casebook of Medical Ethics}

T F Ackerman and C Strong, 240 pages, New York, £32.00, Oxford University Press, 1989

This book consists of a series of medical case histories which can be considered and discussed. The cases were chosen because they posed difficult moral problems for the doctors involved to consider in deciding how to act in managing of each case. Every case description contains a wealth of detail, including many of the complexities of the patient's personal circumstances and a full account of the medical issues involved. Almost all are actual cases of which the authors have personal knowledge.

The cases are grouped together into chapters with a common theme, covering the topics of paternalism, duties to the patient and the family, making decisions for others, medical research, and doctors and third parties.
As well as the case histories, there is a commentary at the end of each chapter which provides guidance on the moral principles involved in the cases.

None of the case histories given are straightforward, either from a medical or a moral perspective. It is fortunate that in practice not all clinical problems pose the same difficulties!

There is no doubt that many teachers and students will benefit from having this source of very detailed case descriptions to consider and discuss together. Analysing each history provides insight into ethical principles and demonstrates that in practice there are often complicating factors that have to be taken into consideration, including the uncertainties inherent in both medicine and ethics. The moral principles involved in each case often appear to be conflicting, and make clear the difficulties faced by the practising doctor.

Of great value are the authors' commentaries at the end of each chapter, which analyse the problems and show ways towards the resolution of the ethical dilemmas that are posed in various situations.

This book is a useful addition to the medical ethics literature both because of the well documented and interesting case histories, and for the commentaries which are lucid and informative. Though mainly of use for those either teaching or learning about health care ethics it will also appeal to medical practitioners, nurses and other health care workers interested in good clinical practice.

RICHARD WEST Consultant and Senior Lecturer Department of Child Health, St George's Hospital Medical School, London SW17

\section{Changing Ideas in Health Care}

Edited by David Seedhouse and Alan Cribb, 236 pages, Chichester, £9.95, John Wiley and Sons, 1989

This book contains a collection of articles which describe attempts to facilitate increased public participation in health care. These have taken place in a variety of social settings including a national heart-health education programme; city and community-based initiatives; and hospital and hospice 